\title{
O minicurso na formação continuada de professores de línguas de uma escola cooperativa: do processo formativo à efetivação da experiência
}

\section{A microteaching in the language teachers continuing education in a cooperative school: from the formative process to the realization of the experience}

\author{
Danielle Cristine Silva ${ }^{1}$ \\ Patrícia Vasconcelos Almeida ${ }^{2}$
}

\begin{abstract}
Resumo
Partimos do pressuposto que a formação de professores deve ocorrer de maneira contínua a fim de considerar as demandas socioeducacionais vigentes. Pensando nessa perspectiva, o objetivo deste artigo é discutir sobre as etapas permeadas ao trabalhar com a ferramenta formativa conhecida como minicurso e produção didático pedagógica a partir dessa experiência na formação do professor em exercício. A abordagem qualitativa da pesquisa privilegia uma discussão sobre a aplicação do minicurso acerca do uso do artefato tecnológico digital webquest a professores de uma escola cooperativa do interior de Minas Gerais e como esse momento formativo influenciou as escolhas e práticas dos professores colaboradores dessa investigação. Como metodologia de geração de dados foram utilizados questionários semiestruturados que viabilizaram uma análise direta da experiência pedagógica vivenciada no momento da aplicação do minicurso. Os resultados indicam o minicurso como influenciador de uma nova prática pedagógica e como contribuidor da formação continuada dos professores de línguas participantes.
\end{abstract}

Palavras-chave: processo formativo; prática pedagógica; tecnologia digital

\begin{abstract}
We start from the assumption that teacher training must take place continuously, in order to consider the current socio-educational demands. Thinking from this perspective, the objective of this article is to discuss the steps chosen by the teacher when working with a formative tool known as microteaching and also discuss teacher's pedagogical didactic production based in the experience of using a Webquest as a didactical tool. The qualitative approach provides a discussion about the experience with the microteaching and how this training moment influenced three teachers of a cooperative school in Minas Gerais choices and practices. As a data generation methodology, semi-structured questionnaires were used, which enabled a

\footnotetext{
${ }^{1}$ Mestra em Educação, graduada em Letras e em Pedagogia e pós-graduanda em psicopedagogia. Universidade Federal de Lavras, Lavras, Brasil, E-mail: danielle.letrasufla@gmail.com

${ }^{2}$ Doutora em Linguística Aplicada e professora associada da Universidade Federal de Lavras. Universidade Federal de Lavras, Lavras, Brasil. E-mail: patricialmeida@ufla.br
} 
direct analysis of the pedagogical experience lived at the time of the application of the minicourse. The results indicate that the microteaching is an influencer of a new pedagogical practice. It also contributed to the continuing education of the language teachers who participated to the process.

Keywords: Formative process; pedagogical practice; digital technology

\section{Introdução}

Em comemoração aos 10 anos do PPGE - Programa de Pós-Graduação em Educação, compartilharemos, neste artigo, um recorte da pesquisa de mestrado realizada entre os anos de 2016 e 2017. O estudo consistiu no diálogo entre as grandes áreas do conhecimento: Educação e Linguística Aplicada e tinha como foco principal compreender as nuances dos trabalhos pedagógicos de professores de línguas - Língua Portuguesa, Língua Inglesa e Redação - quando em contato com práticas mediadas pelas tecnologias digitais, tais como: computadores, tablets e smartphones.

A dissertação, intitulada A webquest na prática pedagógica do professor de línguas: um estudo de caso, defendida no ano de 2017 na UFLA - Universidade Federal de Lavras, postula sobre o uso da tecnologia digital no trabalho docente. A partir desse tema, a pesquisa deu ênfase aos estudos sobre o artefato tecnológico digital conhecido como webquest, que conforme Silva (2017), é um recurso que proporciona uma aprendizagem colaborativa por meio de um processo de ensino baseado na construção do saber. O acesso a ferramenta se dá via internet e pela webquest o professor tem a possibilidade de criar atividades orientadas para que os discentes as realizem.

Com o foco nessa função específica da webquest foi trabalhada a formação continuada dos professores participantes da pesquisa. Para essa proposta de formação continuada foi utilizada como ferramenta formativa um minicurso, que tinha como função primordial oferecer aos professores participantes conhecimentos teórico-práticos sobre a utilização dessa tecnologia digital em sala de aula.

Assim, o presente artigo tem por objetivo compartilhar as etapas permeadas durante o minicurso e a produção didático pedagógica a partir dessa experiência na formação do professor em exercício. 


\section{O minicurso em foco}

Em linhas gerais, o minicurso é um evento de curta duração, que possui como escopo o ensino-aprendizagem de um assunto delineado por seus ofertantes. Ao se pensar em utilizar um minicurso como parte de uma metodologia de trabalho, de ensino e até mesmo de geração de dados científicos, é preciso estruturá-lo de maneira que ele chegue ao seu público de forma clara e com uma linguagem acessível. Neste viés, um minicurso pode ser configurado de diferentes formas, visto que todos os tópicos que o caracterizam em sua construção (área científica, tema, objetivo, público-alvo, duração, meio de divulgação, apresentação, consolidação etc.) são absolutamente interdependentes e variáveis.

Validando essa concepção, o minicurso em pauta tinha uma proposta teórico-prática e por isso, buscou atender as demandas iniciais - teóricas e metodológicas - dos professores de línguas (sujeitos participantes desta investigação) em relação ao uso da tecnologia digital em suas aulas. Na perspectiva teórica, pensava-se em trazer para os professores em formação conhecimentos científicos acadêmicos que validassem o trabalho docente por meio de práticas digitais. Autores como Altoé e Silva (2005) e Vieira-Abrahão (2010) fazem essa validação ao pontuarem os desafios de se oferecer oportunidade de formação docente visando aperfeiçoamento das práticas digitais e ao afirmarem que ensinar utilizando as ferramentas digitais disponíveis é uma tarefa desafiadora, mas eminente no atual contexto educacional.

Embora, em uma visão simplista, a função primeira do professor seja ensinar, ao se pensar um minicurso para uma formação continuada a premissa implícita, pelo menos no contexto de atuação que norteou este artigo, está em proporcionar maneiras para que estes professores compreendam a necessidade de se buscar formas de fazer com que os seus alunos aprendam um conteúdo e tenham o interesse em continuar buscando o aprendizado (LAURIA, ZAMPAR e LEMOS, 2019). Mesmo tendo as tecnologias digitais como ferramentas motivadoras e facilitadoras do processo de ensino-aprendizagem, as quais demonstram estimular o aluno a essa busca contínua de conteúdos, é preciso proporcionar experiências de aprendizagem aos professores e para o contexto de investigação deste artigo, essas práticas são viabilizadas por meio da ferramenta formativa: minicurso.

Vale aqui destacar que os autores supramencionados pautam seus estudos nos preceitos de Kolb (1997), que defende a experimentação como um dos pontos fulcrais do aprendizado. Segundo o modelo de aprendizagem do Kolb, apontado pelos autores, é 
importante que o professor vivencie a experiência de aprender - para o contexto desta investigação um aprender mediado pelas tecnologias digitais - para então adquirir consciência crítica e reflexiva do aprendizado. Ao observar o processo de aprendizagem ao qual estão sendo expostos, os professores refletem sobre a experiência levando em conta diversas perspectivas e criam seus próprios conceitos sobre ela. Com esses conceitos, eles conseguem avaliar as vantagens e os problemas do processo e então são capazes de criar novas experiências.

Corroborando com essa perspectiva reflexiva pode-se mencionar o trabalho de Pimenta e Ghedin (2002), que afirmam que a formação reflexiva do professor não se restringe apenas a aquisição conteudista e a domínio metodológico, mas abrange também o viés reflexivo, crítico e prático, propiciando que o indivíduo distancie, analise, repense e refaça.

Ainda segundo Lauria, Zampar e Lemos (2019) conhecer o ciclo, denominado por Kolb de aprendizagem vivencial ou experimental supramencionado, permite que o professor perceba seus alunos como coparticipantes do processo de ensino-aprendizagem. Por esse motivo, o minicurso foi utilizado como meio de não só oferecer um momento de formação teórica sobre o uso das tecnologias digitais nas práticas pedagógicas, mas também, de experimentação de um artefato tecnológico para o ensino.

Considerando a referida perspectiva metodológica, a demanda da sala de aula do século XXI, cujo foco está diretamente relacionado ao uso das tecnologias digitais, parece exigir que o professor desenvolva habilidades pedagógicas que vão além da exposição teórica do conteúdo. De acordo com Romão e Almeida (2019) quando os professores passam a considerar a possibilidade de modificar metodologicamente suas práticas pedagógicas de acordo com seus múltiplos contextos sociais e recursos pedagógicos (digitais ou não), ele começa a apresentar uma maturidade pedagógica. Segundo as autoras, "essa maturidade é desenvolvida e solidificada a partir e durante os processos de formação, bem como da experiência de docência vivenciada pelo professor" (p.38). Nessa linha de intencionalidade, o minicurso em questão foi pautado no desafio de apresentar um artefato digital - a webquest como uma opção metodológica para criação de atividades para a sala de aula.

Dessa forma, a utilização de um minicurso para capacitar o professor para o uso da webquest coloca o trabalho investigativo em questão no contexto da formação continuada. Uma formação que, segundo Carvalho e Gil-Pérez (2011), visa não apenas o desenvolvimento 
de competências, mas também, como uma preparação contextualizada do sujeito para se tomar decisões práticas a partir de respaldos teóricos.

Nessa perspectiva, os autores postulam que planejar atividades é uma prática formativa básica e torna-se essencial quando se espera um processo de ensino-aprendizagem como forma de construção de saberes por parte do discente. Neste contexto, o professor deixa de ser ministrador de aulas e transmissor do saber, para adotar uma postura de orientador, estabelecendo diálogos e valorizando as contribuições dos alunados. Porém, vale destacar que apesar de o trabalho perpassar a formação de professores, este não é o escopo direto de análise deste artigo, mas sim a práxis dessa formação: o minicurso.

Isto posto, passamos a descrição do minicurso, o qual consistiu-se em dois encontros com duração de três horas cada, que ocorreram no período vespertino, conforme disponibilidade dos três professores de línguas envolvidos os quais integram parte da área de línguas da escola, sendo um professor da disciplina de Língua Portuguesa, um de Redação e um de Língua Inglesa.. Vale a pena destacar que os três professores atuam em uma escola cooperativa, a qual pauta os preceitos de trabalho no cooperativismo, no interacionismo e nas premissas teórico-metodológicas de Paulo Freire.

A escola atende discentes do ensino infantil ao ensino médio e possui uma turma para cada série escolar, a qual é composta, em média, por quatro discentes. As salas possuem uma grande mesa com cadeiras em volta, que acomodam em círculo discentes e professor, o que difere do tradicional layout das salas de aulas. Os professores e os alunos têm acesso à computadores conectados à internet para viabilizar o ensino, seja por meio de notebooks que a escola disponibiliza para serem utilizados nas salas de aulas ou por meio de computador de mesa que a instituição dispõe na sala de artes, seja por meio de notebook pessoal que, por vezes, os discentes e docentes transportam.

No primeiro encontro, a abordagem do minicurso se deteve nas questões teóricas e metodológicas que envolvem o processo de ensino-aprendizagem mediado pelas tecnologias digitais. Para isso, foram elaboradas apresentações em Power Point a fim de explicitar o tema webquest em seus aspectos teóricos e práticos. As considerações teóricas se pautaram nas postulações dos autores Marinho (2001) e Marzano (1992) acerca da temática, apresentando, especificamente, o cunho didático-pedagógico sobre o uso do computador conectado à Internet como artefato para as práticas didáticas. 


\section{OO DEVIR EDUCAÇÃO}

ISSN: 2526-849X

Marinho (2001) de acordo Silva (2017) deixam claro o objetivo didático-pedagógico do computador quando afirma que "um artefato tecnológico visa proporcionar uma aprendizagem colaborativa por meio de um processo de ensino baseado na construção do saber e pode vir a auxiliar no desenvolvimento do pensamento crítico dos discentes, bem como na habilidade de tomada de decisão.” (p. 37). Conforme Marzano (1992):

as atividades realizadas por meio do artefato digital exigem dos discentes as habilidades de: fazer comparações, articulando-as e identificando-as; classificar o objeto estudado em categorias; levantar hipóteses; inferir generalizações; analisar inadequações; abstrair informações; articular perspectivas, identificando-as e analisando-as; e construir alternativas para respaldar as respostas corretas. (SILVA, 2017, p. 37)

Isto posto, ao desenvolver as atividades do primeiro encontro tinha-se a intenção de fazer com que o professor vivenciasse a experiência do uso da tecnologia digital como aluno e pudesse, segundo os preceitos de Kolb (1997), perceber a complexidade da aprendizagem vivenciada. A partir dessa fase, eles poderiam passar para o segundo momento do minicurso com um discernimento dos entraves não só destinados ao ensino, mas também, da aprendizagem mediada pelas tecnologias digitais, tais como funcionamento da webquest, partes que a constitui, maneiras de utilização, metodologias possíveis a serem aplicadas nas aulas, dentre outros conhecimentos prévios importantes.

Portanto, no segundo encontro, a ênfase foi no viés prático, composto por um vídeo tutorial que ensinava aos professores como construir uma webquest por meio do Google sites. Além dessa ferramenta elucidativa, também foi utilizado um exemplo de webquest construído pela pesquisadora no planejamento e apresentado no minicurso, especificamente com a função de explicar cada etapa trazida pelo artefato, conforme figura abaixo.

Figura 1 - Exemplo de webquest-apresentação 


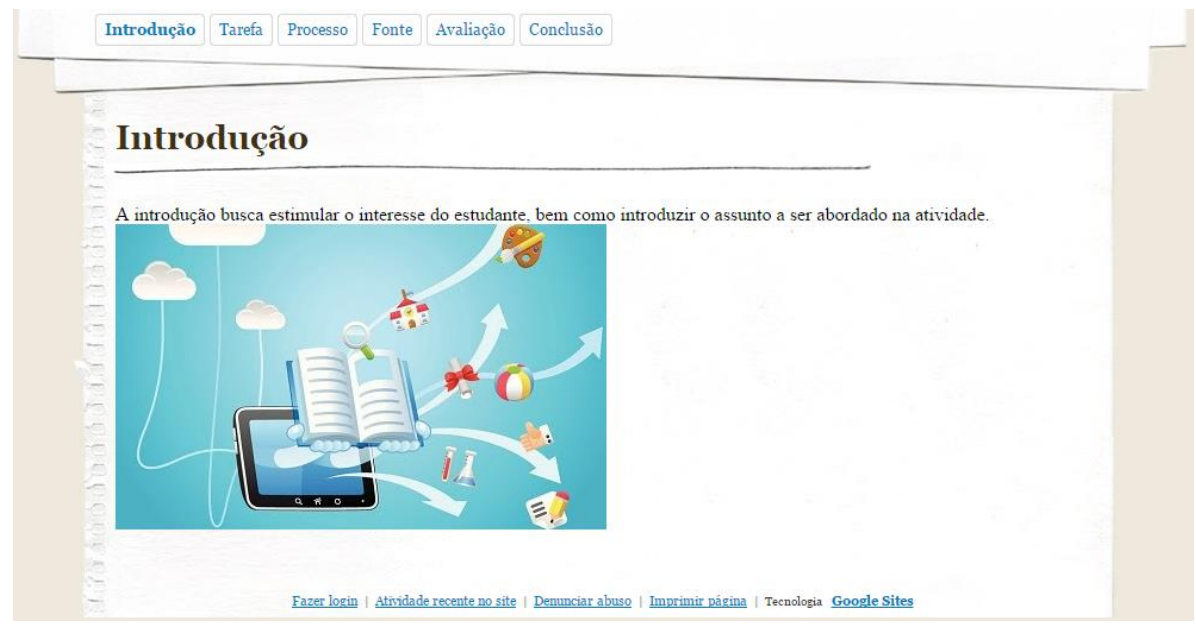

Fonte: Silva (2016).

A partir do exemplo de webquest apresentado pela pesquisadora, os professores puderam visualizar as etapas que o artefato disponibiliza para se construir uma aula orientada via webquest, são elas: introdução, tarefa, processo, fonte, avaliação e conclusão. Após esse primeiro contato, quando foi explicado e apresentado aos professores como cada uma dessas etapas funcionam, os docentes simularam a elaboração de uma atividade para ser executada por meio da webquest.

Ao executarem essa atividade, eles tiveram a oportunidade de explorar o artefato com o auxílio da pesquisadora, seu design, a inserção de figuras, direcionamento para sites de pesquisa, dentre outras possibilidades. Neste momento, a intenção era de oferecer aos professores a oportunidade de utilizar o artefato tecnológico de maneira crítica e reflexiva, de forma a auxiliar o processo de desenvolvimento de um letramento digital, isto é, nos novos modos de ler e produzir textos e que abarca a multiplicidade de textos transpostos para o âmbito digital, segundo salienta Rojo (2013). Para que assim eles pudessem então utilizar na fase de preparação da sua própria aula, conforme esperado a partir de um curso de formação continuada.

\section{Da experimentação à prática: uma análise qualitativa}

A metodologia de pesquisa empregada, para a realização do trabalho investigativo que culminou neste artigo, contempla o método qualitativo e interpretativo, uma vez que o 
objetivo da investigação não foi quantificar os participantes, mas descrever o critério de escolha deles, bem como compreender a forma como eles conduzem o processo de ensinoaprendizagem levando em consideração a percepção da cultura e do cotidiano em que estão inseridos.

A pesquisa compreende o estudo de caso por abarcar a utilização de poucos objetos, de forma a permitir um amplo e detalhado conhecimento, além de, conforme Yin (2005), por ser empírica e permitir o estudo de um fenômeno contemporâneo.

Dito isto, passamos à descritiva da prática da pesquisa empreendida. Posteriormente a experiência do minicurso, os professores colaboradores da pesquisa elaborariam e aplicariam uma atividade online para os estudantes desenvolverem por meio da webquest. O professor de Língua Portuguesa optou por trabalhar com o assunto funções da linguagem, o professor de Redação trabalhou com a temática sobre conto fantástico e o professor de Língua Inglesa trabalhou com o conteúdo verbos. Vale destacar que os conteúdos escolhidos e abordados pelos professores já faziam parte do plano de ensino previsto para o ano letivo.

De posse do conhecimento gerado pelas experiência vivida durante o minicurso, de que a webquest é um artefato tecnológico digital disponível online, que permite que qualquer indivíduo possa acessar e criar uma aula orientada, cujo o link gerado no momento de sua criação pode ser acessado e o discente ter uma aula descrita passo a passo via internet, os professores passaram à construção de ambiente de aprendizagem.

De posse do link do exemplo da webquest apresentada no minicurso https://sites.google.com/site/webquestexemplominicurso/home, os professores puderam revisitar a página e guiar seus passos para a criação da sua própria página. Eles puderam lembrar pelo modelo da webquest previamente apresentado, que ela pode ser subdivida por: introdução, tarefa, processo, fonte, avaliação e conclusão. É importante salientar que utilizamos a análise das webquests produzidas pelos professores a fim de exemplificar o produto gerado pelo minicurso.

Essa subdivisão é normalmente a mais usada e foi utilizada na íntegra pelo professor de Língua Portuguesa na montagem de sua página, que trabalhou o tema funções da linguagem. O professor de Língua Inglesa substituiu pelos nomes: home, task, step-by-step, source, assessmente conclusion e trabalhou verbs quest. $\mathrm{O}$ professor de Redação utilizou: introdução; vamos ver se eu entendi...; vai uma ajudinha aí?; você, escritor; e autoavaliação e trabalhou o conto fantástico. Percebe-se nesse momento que a estrutura apresentada é 
apenas um guia e não precisa ser seguida à risca. Assim, o professor pode criar o título, subtítulos e design da página conforme preferência e objetivo. Neste momento, os professores percebem que a webquest permite a construção da página online de maneira livre, como pontua o professor:

"Possibilidade de disponibilizar recursos diversos como vídeos, textos, imagens e hiperlinks para os alunos." (Professor de Redação)

O professor de Redação trabalha com o ensino fundamental II e o ensino médio, a aula mediada pela webquest foi realizada com quatro discentes do oitavo ano do ensino fundamental II. Ele produziu a webquest intitulada Conto Fantástico, disponível em: https://sites.google.com/site/contofffantastico/home, de acordo com a figura abaixo:

Figura 2 - Webquest intitulada Conto Fantástico.

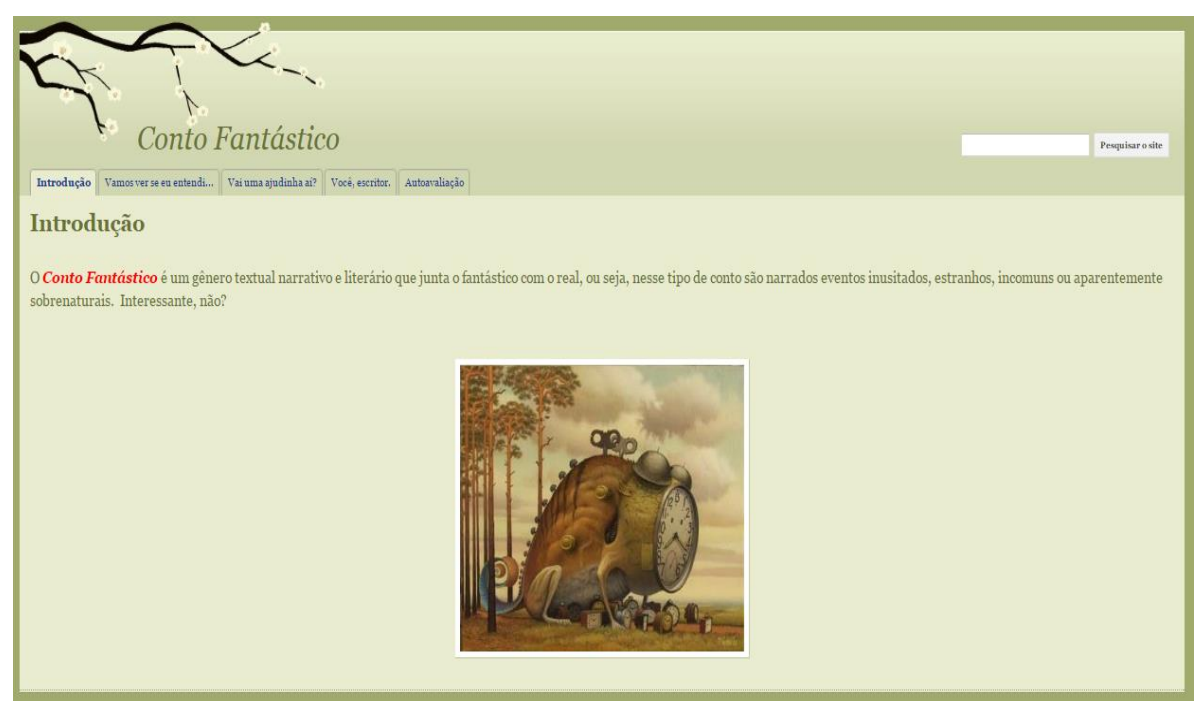

Fonte: Professor de Redação (2016).

A webquest acima, apesar de utilizar outras nomenclaturas compreende introdução, processo, fonte e avaliação, não abordando os tópicos tarefa e conclusão, que foram sugeridos no minicurso. Era esperado que as instruções para o estudo do conteúdo fossem dadas via ferramenta, contudo foi possível constatar que a aula não apresentou um desfecho e nem uma delineação lógica do objetivo do estudo via artefato tecnológico. Também não ficou claro o local onde os discentes desenvolveriam a atividade proposta e se teriam que apresentar alguma forma de retorno do conteúdo apreendido ao professor e aos demais discentes, aspectos estes que deveriam estar definidos para os alunos. Os demais tópicos foram bem 


\section{QO DEVIR EDUCAÇÃO}

ISSN: 2526-849X

explorados, principalmente os links de direcionamento para pesquisas online. Assim, foi deixado à mostra que o professor ressignificou a parte teórica acerca da ferramenta exposta no minicurso, uma vez que ele aplicou na aula via webquest os tópicos os quais julgou importantes quando planejou a aula via artefato.

O professor de Língua Inglesa ministra aulas para o ensino fundamental II e ensino médio e trabalhou a webquest intitulada English Verbs Quest, disponível em: https://sites.google.com/site/englishverbsquest/home, com dois alunos da turma do primeiro ano do ensino médio. A imagem abaixo mostra o layout da página criada:

Figura 3 - Webquest intitulada English Verbs Quest.

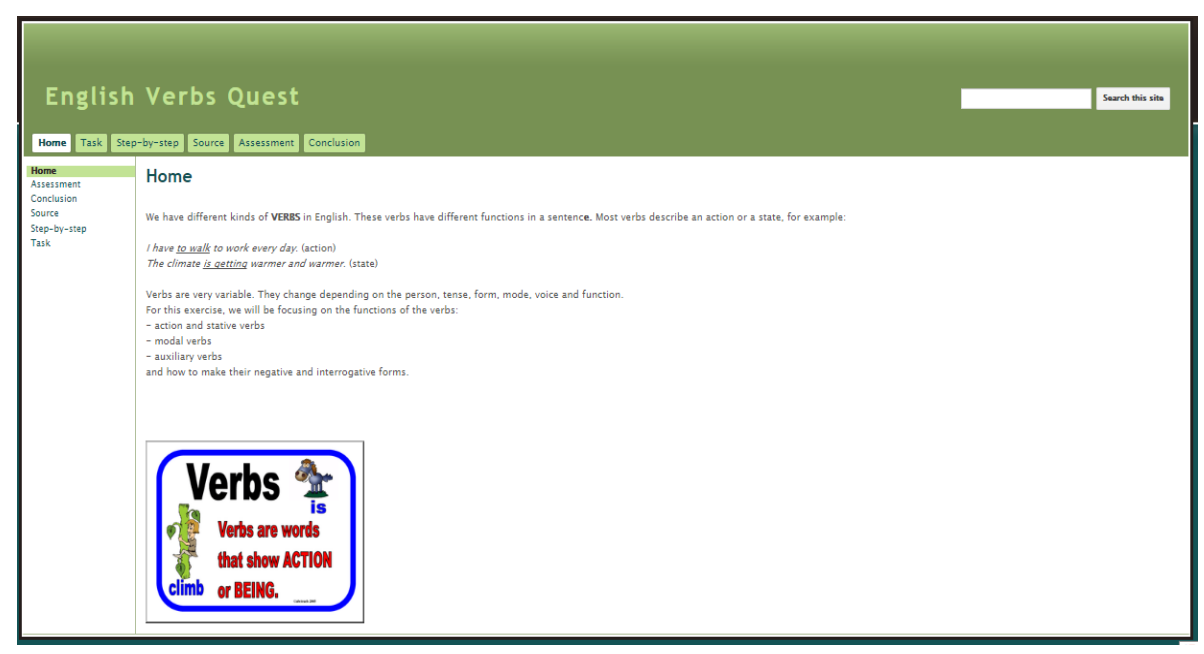

Fonte: Professor de Língua Inglesa (2016).

Analisando as etapas da atividade empreendida na webquest, pode-se dizer que ela contemplou, de acordo com o minicurso, todos os tópicos típicos de uma webquest, as nomenclaturas permaneceram as mesmas, sendo apenas traduzidas para a Língua Inglesa. A partir da observação dos comandos dados pelo professor para a realização da atividade, por meio da diagramação das atividades na página, bem como embasada na parte teórica acerca da webquest apresentada no minicurso, pode-se considerar que o professor explorou a maioria dos tópicos, faltando apenas a conclusão e estimulou a cooperação e interlocução entre discentes e professor via artefato tecnológico. Portanto, o docente empreendeu na aula via artefato características tradicionais do uso da ferramenta, como exposto no minicurso.

O professor de Língua Portuguesa trabalha com discentes do ensino médio e ministrou a aula mediada pela webquest intitulada Funções da Linguagem, disponível em: 


\section{OO DEVIR EDUCAÇÃO}

ISSN: 2526-849X

https://sites.google.com/site/figurasdelinguagemi/home para cinco discentes do terceiro ano do ensino médio. Abaixo apresentaremos o layout da webquest criada pelo professor:

Figura 4 - Webquest intitulada Funções da Linguagem.

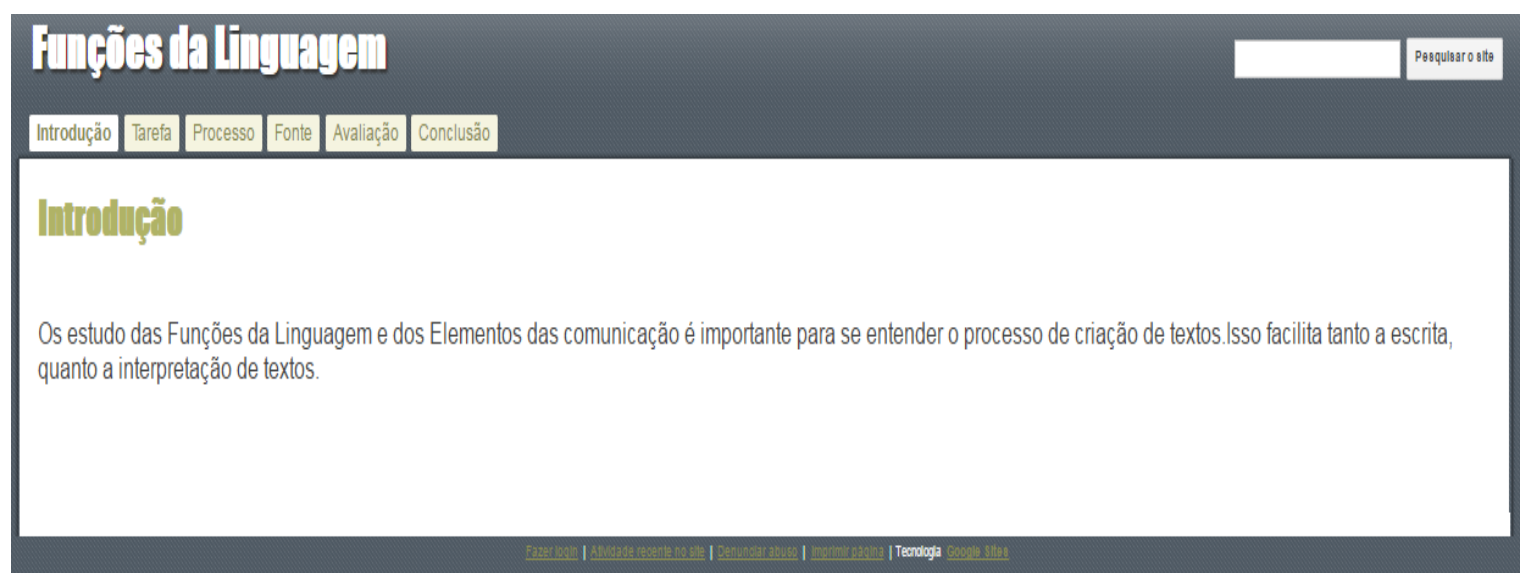

Fonte: Professor de Língua Portuguesa (2016).

Analisando todo o conteúdo das outras páginas da webquest é possível perceber que o professor optou por seguir os subtítulos da webquest tradicional, apresentada como modelo no minicurso e no próprio site. Contudo, os tópicos avaliação e conclusão apesar de serem iguais não contemplaram a proposta estipulada pelos itens, conforme exposto na teoria acerca da webquest no minicurso. No item avaliação, deveria ser avaliado o conteúdo trabalhado e o professor explicou ao discente como ele seria avaliado. E no item conclusão, o professor fez uma autoavaliação, em vez de sintetizar o aprendizado do discente em relação ao tema.

Essa atitude do professor demonstrou ser uma alternativa interessante para as funções pré-determinadas no modelo, uma vez que permite a análise e a reflexão do discente e do professor em relação ao processo de ensino-aprendizagem. Essa postura do professor faz com que se considere uma autonomia dele para a tomada de decisões sobre como proceder enquanto responsável pelo processo de ensino-aprendizagem em questão, conforme postula Lauria, Zampar e Lemos (2019).

É importante destacar, que a análise das webquests teve o produto da prática esperado embasado nas postulações dos autores Marinho (2001) e Marzano (1992) e nos conteúdos trabalhados na ministração do minicurso. Dessa forma, era esperado que os professores cumprissem com todos os escopos das etapas tradicionalmente trazidas pela webquest, de modo a possibilitar o ensino-aprendizagem passo a passo orientado pelo artefato tecnológico 
digital. Assim, podemos considerar que a prática, demonstrada pelos professores por meio da webquest, foi determinada pelo que eles já sabiam e dominavam, duas ações que foram construídas durante o minicurso.

Analisando as três webquests apresentadas, produto do minicurso, podemos inferir que a característica formativa elencada por Carvalho e Gil-Pérez (2011) foi abordada, no que concerne à atividade de planejar. No contexto da investigação, foi possível verificar que os professores planejaram a atividade, almejando a construção do saber dos discentes, destoando da atividade de preparar aula sem elo com o conteúdo curricular, haja vista o conteúdo trabalhado fazer parte da grade curricular já preestabelecida pelos professores.

Essa conclusão nos permite fazer uma relação com os preceitos de Lauria, Zampar e Lemos (2019) ao defenderem os benefícios de se conhecer o ciclo de aprendizagem vivencial ou experimental de Kolb (1997), pois ele proporciona que o professor perceba seus alunos como coparticipantes do processo de ensino-aprendizagem. Exatamente o que parece ter acontecido nesse momento da investigação, uma vez que os estudantes atuaram de maneira autônoma na construção do saber, perpassando a aula orientada e navegando entre os hiperlinks de forma protagônica. Mas a aula por meio do artefato viabilizou a colaboração entre docente e discente.

No que concerne ao planejamento da atividade, podemos inferir que a experiência de utilização da webquest, a partir do minicurso, pôde contribuir para a formação continuada dos professores de línguas, uma vez que a alteração no artefato pedagógico proporcionou uma nova perspectiva de planejamento, haja vista as novas ferramentas disponíveis. Novamente temos a relação entre a experiência vivida e a modificação na prática pedagógica, assim como postulado acima por Lauria, Zampar e Lemos (2019). Portanto, as aulas planejadas pelos professores por meio da webquest foram resultados de sua experiência de formação continuada por meio do minicurso e resultado da percepção sobre o modo que o uso da webquest pode influenciar a prática pedagógica do professor.

Seguindo no processo de análise dos dados, após o planejamento e realização da atividade mediada pela webquest, os professores tiveram a oportunidade de apontar suas considerações sobre essa experiência. Eles salientaram que: (i) webquest auxilia o trabalho do professor de línguas dependendo da utilização, funcionamento e sucesso da aplicação; (ii) o artefato tecnológico traz maior autonomia para o estudante; (iii) foi a primeira vez que utilizaram essa tecnologia e afirmam que ela auxilia na formação continuada no que tange um 
recurso para integrar e enriquecer a aula; e (iv) a webquest contribuiu para a formação continuada, mais especificamente, como um recurso a mais de ensino, principalmente se o professor precisar se ausentar ou ministrar uma aula a distância, em conformidade com os trechos subsequentes:

\footnotetext{
"Depende da maneira como é utilizada, do seu funcionamento e do sucesso da sua aplicação." (Professor de Língua Inglesa)

"É uma ferramenta interessante que pode integrar a formação do professor e enriquecê-la (...).” (Professor de Língua Inglesa)

"A diferença está em proporcionar mais autonomia ao aluno." (Professor de Língua Inglesa)

"É uma ferramenta muito interessante ao solicitar aos alunos trabalhos a serem feitos em casa, ou em aulas em que o professor esteja ausente." (Professor de Redação)
}

Os excertos acima elucidam a experiência de trabalhar com a webquest a partir do minicurso e comprovam o aspecto reflexivo que influenciou a criação de tais observações, as quais poderão vir a modificar suas ações didático pedagógicas quando utilizando as tecnologias digitais e desta forma criar novas experiências em sala de aula (LAURIA, ZAMPAR, LEMOS, 2019).

Assim, é possível inferir que o ensino-aprendizagem mediado pela webquest, bem como o minicurso influenciaram a formação continuada desses professores de línguas, quando os desafiou a planejar, elaborar e pensar sobre essa vivencia de prática pedagógica. A experiência os tornaram mais críticos em relação ao processo de ensinar-aprender, assim como mais reflexivos nas ações em sala de aula, no que tange o posicionamento problematizador ao ministrar uma aula a partir de um artefato digital, discussão trazida por Pimenta e Ghedin (2002). Desse modo, podemos considerar que o minicurso ministrado contribuiu para a formação do professor, uma vez que o artefato webquest em si não opera mudanças, mas sim, o uso didático a partir de sua utilização.

\section{Considerações finais}


Considerando as análises acerca das aulas elaboradas por cada um dos professores participantes da investigação em questão, foi possível destacar que o minicurso empreendido contribuiu para a formação do professor, uma vez que a análise demonstrou que foi via minicurso, que o professor foi capaz de criar uma nova experiência e realizar uma prática pedagógica por meio do artefato tecnológico digital. Além disso, foi perceptível uma mudança de postura quanto à manifestação do uso de suas habilidades relativas ao letramento digital, bem como à multimodalidade e à multissemiose $\mathrm{e}^{3}$ ao montarem a aula na webquest .

É possível inferir que essas modificações e manifestações só foram viabilizadas devido a experiência vivenciada no minicurso. Durante esse momento, os professores demonstraram consciência da mídia que lhes foi apresentada, assim como criaram aulas orientadas via internet-webquest de modo a utilizar linguagem verbal, linguagem não verbal e linguagem sonora, bem como relacionaram palavras, cores, fotografias e vídeos de maneira a buscar atender a demanda da atividade programada para a aula planejada.

Desse modo, consideramos que isoladamente a tecnologia digital em questão não opera mudanças. O conhecimento de seus mecanismos, junto ao cunho didático que se explora dela, elementos que foram apresentados e incentivados ao uso durante o minicurso, viabilizaram que os professores efetivassem nas webquests elaboradas a possibilidade de desenvolver a autonomia dos estudantes. Nesse sentido, a maneira como os professores operaram a tecnologia parece ter oportunizado a eles uma mudança na perspectiva sobre o processo de ensino-aprendizagem mediado pela tecnologia digital.

\section{Referências Bibliográficas}

ALTOÉ, Anair.; SILVA Heliana da. O desenvolvimento Histórico das novas tecnologias e seu emprego na educação. In ALTOÉ, Anair. COSTA. Maria. Luiza. Furlan TERUYA, Tereza. Kazuko. Educação e novas tecnologias. Maringá: EDUEM, 2005.

\section{CARVALHO, A. M. P. de; GIL-PÉREZ, D. Formação de professores de ciências:} tendências e inovações. São Paulo: Cortez, 2011.

\footnotetext{
${ }^{3}$ A multissemiose pode ser compreendida como sendo a coexistência de uma ou mais linguagens em um texto, compreendendo dentre elas a linguagem não verbal, a linguagem verbal e a linguagem sonora. E a multimodalidade é conceituada como sendo os textos que relacionam as palavras, as imagens, as cores, os gestos, os sons e as falas. Conceito abordado por Rojo (2009).
} 
KOLB, David. Allen. A gestão e o processo de aprendizagem In: STARKEY, Ken.(editor). Como as organizações aprendem: relato de sucesso das grandes empresas. São Paulo: Futura, p.321-341, 1997

LAURIA, Rodrigo Linhares, ZAMPAR, Douglas, LEMOS, Washington de Macedo. A mais valiosa missão do professor. In: NEVES, Vander José das; LIMA, Maria Tereza; MERCANTI, Luiz Bittencourt; COSTA, D. J. A Metodologias Ativas: inovações educacionais no ensino superior, Campinas; SP: Pontos Editores, 2019

MARINHO, Simão Pedro Pinto. WebQuest - um uso inteligente da Internet na escola. Caderno do Professor, n.7, p.55-64, Fevereiro, 2001.

MARZANO, Robert. J. A Different Kind of Classroom: Teaching with Dimensions of Learning. Alexandria, VA (USA): ASCD. 1992.

PIMENTA, Selma. G. e GHEDIN, Evandro. Professor reflexivo no Brasil. São Paulo: Cortez, 2002.

ROJO, Roxane. Letramentos múltiplos, escola e inclusão social. São Paulo: Parábola Editorial, 2009.

\section{3.}

. (Org.). Escola conectada: os multiletramentos e as TICs. São Paulo: Parábola,

ROMÃO, Janúzia. N. S.; ALMEIDA, Patricia. V. Formação do professor para o uso das tecnologias digitais. MOARA - Revista Eletrônica do Programa de Pós-Graduação em Letras. n. 51, p.32-54, ago. 2019. 2 Disponível em <https://periodicos.ufpa.br/index.php/moara/article/view/7329/5625>. Acesso em: 28 ago. 2019. DOI: http://dx.doi.org/10.18542/moara.v1i51.7329.

SILVA, Danielle. C. A webquest na prática pedagógica do professor de línguas: um estudo de caso. 2017. Dissertação (Mestrado em Educação) - Departamento de Educação, Universidade Federal de Lavras, Lavras.

VIEIRA-ABRAHÃO, Maria. Helena. A formação do professor de línguas: passado, presente e futuro. In: SILVA, Kleber. A. (org.). Ensinar e aprender línguas na contemporaneidade: linhas e entrelinhas. 1 ed. Campinas: Pontes Editores, p. 225-234. 2010.

YIN, R. K. Estudo de caso: planejamento e métodos. 3. ed. Porto Alegre: Bookman, 2005. 